\title{
Morphology of Human Insula in Iranian Population and its Relationship with Sex, Age, and Handedness: an Imaging Anatomical Study
}

\author{
Mohammad Ali Atlasi ${ }^{1}$, Maryam Montazeri ${ }^{2}$, Esmaeil Fakharian ${ }^{3}$, Hossein Akbari ${ }^{4}$, Hamid \\ Reza Talari $5^{*}$ \\ ${ }^{1} \mathrm{PhD}$, Anatomist, Associate Professor, Anatomical Sciences Research Center, Kashan University of Medical Sciences, Kashan, \\ Iran \\ ${ }^{2}$ MD, General Physician, Faculty of Medicine, Kashan University of Medical Sciences, Kashan, Iran \\ ${ }^{3}$ MD, Professor of Neurosurgery, Department of Neurosurgery, Kashan University of Medical Sciences, Kashan, Iran \\ ${ }^{4} \mathrm{PhD}$, Assistant Professor, Bio Statistical Department, Faculty of Health, Kashan University of Medical Sciences, Kashan, Iran \\ ${ }^{5}$ Radiologist, Associate Professor, Radiology Department, Faculty of Medicine, Kashan University of Medical Sciences, \\ Kashan, Iran \\ * Corresponding Author Address: Anatomical Sciences Research Center, Kashan University of Medical Sciences, Kashan, \\ Iran. P.O.Box: 8715988141. Tel:+989126017908, Fax:+983155541112, E-mail: talari_hr@kaums.ac.ir; talarihr@gmail.com
}

Article Type: Research Article

Received: February 15, 2017, Last Revised: April 17, 2017, Accepted: May 1, 2017, Published: June 30, 2017

\section{Abstract}

Background and Aim: Topography of the human insula has occasionally been studied in different populations. The purpose of this study was to evaluate the morphology of human insula in Iranian population and its relationship with sex, age, and handedness via magnetic resonance imaging.

Methods and Materials/Patients: In our study, 380 normal magnetic resonance imaging were enrolled. The number of short and long insular gyri, as well as their relationship with sex, age, hemispheres and handedness were assessed.

Results: No significant differences were seen in number of insular gyri among right and left hemispheres, and males and females, but gyri number of left insula in right handers were significantly more than that in left handers. Maximum anterior - posterior distance of base of insula was longer in male and left insula compared to female and right insula, respectively. Younger individuals had more gyri than the older ones. The middle short insular gyrus can be absent more frequently than anterior and posterior short gyri.

Conclusion: The sagittal magnetic resonance imagings in our study can be appropriate for numbering the insular gyri and help to understand the complicated anatomical structures of insula. The findings of this study demonstrate an insular gyri pattern of handedness and age-related morphology in Iranian population, with similar gyri pattern in both males and females.

Keywords: Insular Cortex; Human; MRI; Morphology

Please cite this paper as: Atlasi MA, Montazeri M, Fakharian E, Akbari H, Talari HR. Morphology of Human Insula in Iranian Population and its Relationship with the Sex, Age, and Handedness: an Imaging Anatomical Study. Iran J Neurosurg. 2017:3(1):15-20

\section{Introduction}

The insula was first described by Johann Christian Reil early in the nineteenth century (1809) [1]. The human insula is a part of the cerebral cortex, located deeply in the floor of the sylvian fissure and covered by the frontal, parietal and temporal opercula [2]. A vascular network is overlaid on its lateral surface composed by the middle cerebral artery collaterals and superficial and deep middle cerebral veins [3]. This cortical area has reciprocal connections with reticular formation nuclei, cerebral cortex, thalamus, and hypothalamus $[4,5]$ and it is involved in motor, sensory, cognitive and visceral functions [2]. The insula plays an integrative role in afferent and efferent signals from and to cortical and limbic areas, and it is the location of gustatory cortex, language area and vestibular integration [6]. The human insula is one of the most left-biased structures in brain [7]. Dominance of the insula is related to lateralization of the inferior part of this lobe [8]. Based on the degree of granularity, the insular cortex is divided into several subdivisions with a postero- 
dorsal to antero-ventral orientation of hypergranular, granular, dysgranular and agranular fields [9]. A combination of genetic and environmental factors may result in insular morphology and its gyral pattern differences in human populations. Human insula as a trapezoidal shape is limited by three peri-insular sulci. The central sulcus of insula divides the insular cortex into anterior and posterior lobes. The anterior lobe includes anterior, middle, and posterior short gyri demarcated by the anterior and precentral insular sulci. The posterior insula includes anterior and posterior long gyri demarcated by the postcentral insular sulcus [10]. Gross insular morphology has been explained in many anatomical and surgical studies $[1,3,10,11]$. Although there are several reports about the insular anatomy; however, imaging anatomy of the human insula is not well described. Insular morphological characteristics and the number of gyri have not been demonstrated sufficiently in MRI studies, which are widely used for clinical and diagnostic purposes. This study provides MRI anatomical information of the insula in Iranian population which may be useful for anatomists, radiologists and neurosurgeons.

\section{Methods and Materials/Patients}

This study was conducted in Departments of Radiology and Anatomy of Kashan University of Medical Sciences (KAUMS), Iran. Scientific and ethical approval of the study was taken from the Research Committee of Medical Faculty of KAUMS. Among the digital archive of Radiology Department containing 1.0 T, T2-weighted, three $\mathrm{mm}$ sagittal sections of brain magnetic resonance images (MRI) were used, and 380 consecutive MRIs (145 males and 235 females) without lesions or malformations were selected randomly. Information including age, sex, handedness, hemispheres and insular morphology were recorded and statistically analyzed.

Maximum anterior-posterior (Max A-P) distance of base of insula parallel with superior limiting sulcus was measured in both hemispheres and the average was calculated.

In each hemisphere, insular topography was evaluated for the anterior short gyrus (ASG), middle short gyrus (MSG), posterior short gyrus (PSG), anterior long gyrus (ALG), posterior long gyrus (PLG), Heschl's gyrus (HG), and central sulcus (CS) and scored as "well seen", "poorly seen", "not seen" and "single" or " bifid".

For analyzing the differences between male and female, right and left sides and in different age groups, student T-test, one way ANOVA and Tukey's post-hoc test were applied. The results were expressed as mean $\pm \mathrm{SD}$. P-value less than 0.05 was considered statistically significant $(\mathrm{P}<0.05)$.

\section{Results}

Mean number of insular gyri was 4.43 . This value was 4.42 and 4.44 for right and left insula, respectively (Figure 1). This difference was not statistically significant $(\mathrm{P}<0.5)$.

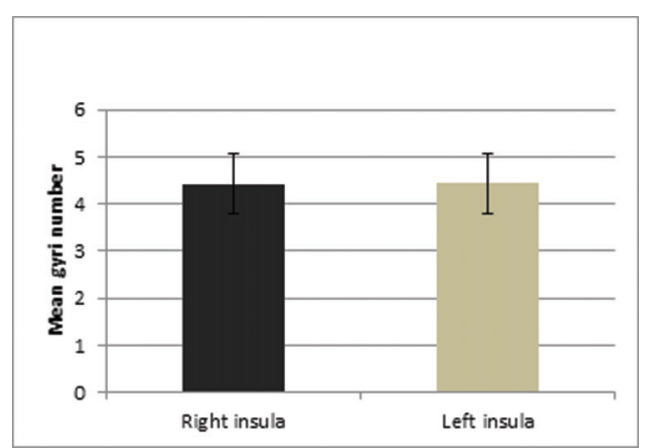

Figure 1. Mean Gyri Number of Right and Left Insula

The mean numbers of insular gyri in right and left hemispheres in males $(n=145)$ were 4.45 and 4.5, respectively, and for females $(n=235) 4.4$ in both hemispheres. The differences in the number of insular gyri between male and female groups and in right and left hemispheres were not statistically significant. The highest insular gyri number was five, ranging from three to five in both hemispheres (Table 1).

$$
\begin{gathered}
\text { Table 1. Insular Gyri Number on MRI in Right } \\
\text { and Left Insula }
\end{gathered}
$$

\begin{tabular}{|c|c|c|}
\hline Gyrus Number & Right Insula & Left Insula \\
\hline 3 & $29(7.6 \%)$ & $30(7.9 \%)$ \\
\hline 4 & $165(43.4 \%)$ & $152(40 \%)$ \\
\hline 5 & $186(48.9 \%)$ & $198(52.1 \%)$ \\
\hline
\end{tabular}

Max A-P distances in left and right insular bases were $48.25 \pm 4.01 \mathrm{~mm}$ and $47.39 \pm 3.98$ 
$\mathrm{mm}$, respectively $(\mathrm{P}<0.001)$ (Figure 2). The mean A-P distance in male and female population on right insular base was $48.44 \pm 4.37 \mathrm{~mm}$ and $46.75 \pm 3.57$ $\mathrm{mm}$, respectively, and in left insular base $49.72 \pm 4.36 \mathrm{~mm}$ and $47.34 \pm 3.49 \mathrm{~mm}$, respectively. These values are higher in men than those in women $(\mathrm{P}<0.001)$ (Figure 3$)$.

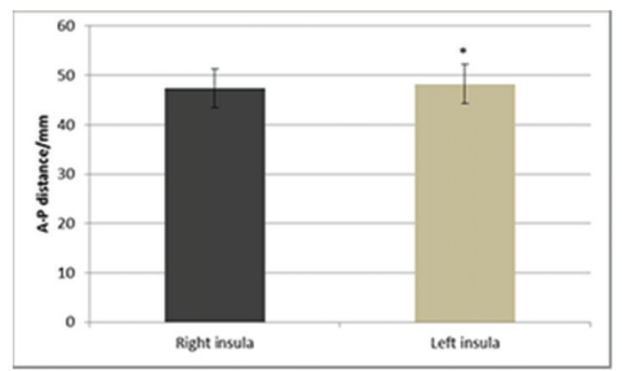

Figure 2. Max A-P Distances of Right and Left Insular Base. A-P Distance of Left Insula is Longer than that of Right Insula $(* \mathbf{P}<\mathbf{0 . 0 0 1})$

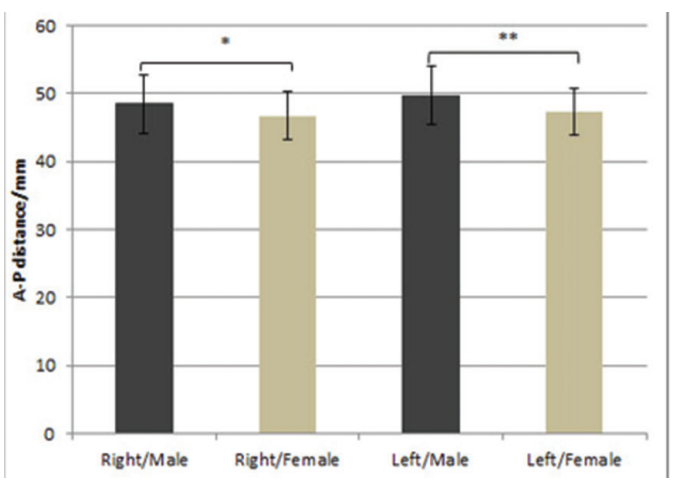

Figure 3. Max A-P Distances of Right and Left Insular Base in Males and Females $(*, * * \mathbf{P}<0.001)$

In present study, right and left handers were $87 \%$ (331 individuals) and 6.8\% (26 individuals), respectively. The mean gyri number of left insula in right and left handers were $4.49 \pm 0.57$ and $4.38 \pm 0.71$, respectively $(\mathrm{P}<0.006)$, and right insula in right and left handers $4.43 \pm 0.61$ and $4.5 \pm 0.7$, respectively $(\mathrm{P}>0.2)$ (Figure 4).

Mean gyri number in cases under 40 years was $4.5 \pm 0.61$, in cases 40 to 59 years $4.41 \pm 0.61$ and in cases above 60 years $4.25 \pm 0.68$. The difference between gyri numbers in the cases under 40 years and those over 60 years was significant $(\mathrm{P}<0.01)$ (Figure 5).

Anterior and posterior short and long insular gyri were seen in all cases, but middle short insular gyrus in right and left hemispheres was not visible in $46.8 \%$ and $43.4 \%$, respectively. This gyrus was absent in $39.3 \%$ of men and $48.7 \%$ of women. We found a single case (a 54-year-old man) whose MRI revealed two right insular gyri and four left insular gyri (Figure 6).

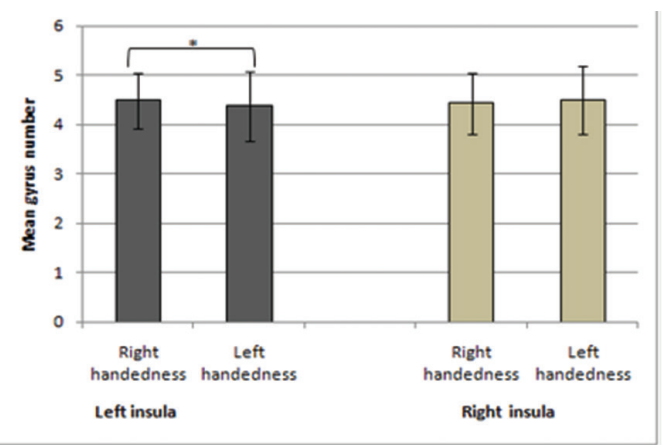

Figure 4. Mean Gyri Numbers of Right and Left Insula in Right and Left Handers. The Number of Gyri in Dominant Hemisphere of either Left or Right Handers was Significantly Higher than that of the Non-dominant Hemispheres $(* \mathbf{P}<0.006)$.

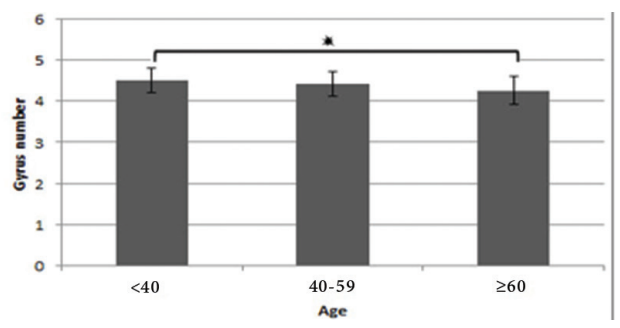

Figure 5. Mean Gyri Number of Insula in Three Age Groups. This Value in the Group under 40 Years in Comparison with those above 60 Years was Significant $(\mathbf{P}<0.01)$

The individual gyri and sulci in right and left insula on sagittal MR images are detailed in table 2.

\section{Discussion}

Human insular morphology in various populations is correlated to different factors. It is reported that the differences in cognitive processes between different populations may be correlated with brain structure [12]. Brain morphology and cortical surface area are influenced by genetic, ethnic and cultural factors [12,13]. The average number of insular gyri has been reported five [6], and our study confirmed it. Our radiological and anatomical study showed that the mean number of insular gyri was similar in left and right hemispheres, and the 
difference between them was not significant. This finding is in contrast to the difference between the volume of right and left insula [14] and compatible with the findings of Mavridis et al. who reported that the left and the right insula had 4.46 and 4.39, respectively [15].

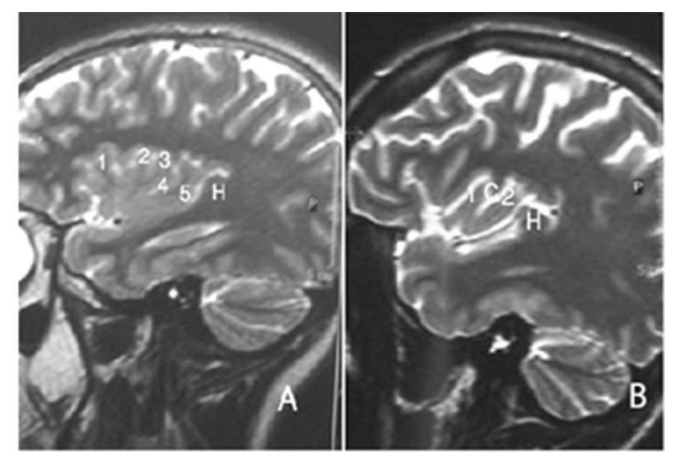

Figure 6. T2-weighted Sagittal MRI Sections A. Imaging Anatomy of the Normal Insula in a 15-year-old Female. The Sections Demonstrate the Anterior (1), Middle (2), and Posterior (3) Short Gyri, Anterior (4) and Posterior (5) Long Gyri. The HG (H) Lies Immediately behind the PLG (5) and Marks the Posteroinferior Border of the Insula. B. Right Insula with the ASG (1) and the ALG (2) in a 54-year-old Man. Central Sulcus (C) has Separated the Two Gyri. The HG (H) Lies behind the ALG (2).

The results of this study indicated that the gyri number of the insula is slightly more in men than that in women, but these differences were not significant. Another study has also shown that males have almost one insular gyrus (0.59) more than females one [15]. Kennedy et al. reported that males insular volume is more than females one $\left(17.6 \mathrm{~cm}^{3}\right.$ versus $\left.16.9 \mathrm{~cm}^{3}\right)$ [16]. In our study, insular A-P length in males was more than that in females, which may be an evidence for difference in the surface and volume of insula between the two sexes in Iranian population. This needs more detailed assessment with higher resolution MRI with thinner sections in different planes.

In our study, $51 \%$ of the cases had insular gyri number of five (three short gyri and two long gyri). In MRI, MSG may not be distinguished. In our study, this gyrus was not seen in $45 \%$ of the cases. The single case, where MRI showed two right insular gyri, may be a normal anatomic variation. Kennedy et al. introduced an MRI-based method for measurement of human cortical topography [16]. Although MRI provides the capacity to visualize morphological details in vivo [17], it may underestimate the real insular gyri number compared with practical anatomy [15], and present study is compatible with this viewpoint. Previous reports have demonstrated that many insular features displayed by MRIs are comparable with findings of brain dissection $[6,15]$. The brain dissection has revealed the number of insular gyri be exactly five [15].

MRI data have identified brain asymmetries [17]. Few investigations have evaluated the morphological asymmetries in the insula. In present study, the gyri number of the left insula in right-handers was significantly more than that of lefthanders and correlated with the handedness (Figure 4). These data represented that righthanders activated left lateralized in insula [18]. The relationship between handedness and brain asymmetry may be related to hand preference [19]. Chiarello et al. suggested that hand preference is a main contributor to individual differences in structure of insula [20]. Structural asymmetries of insular cortex have been pertained to the lateralization of language in right and left-handers [15]. Differences of insular gyri number between left- and right-handers may be linked to structural inter-hemispheric differences of the insula and to the lateralization of cerebral functions [7].

Aging is associated with brain atrophy [21]. Age-related gray matter declines in the insula, cerebellum, basal ganglia, prefrontal area and thalamus [22-24]. In present study, it was shown that younger subjects have more insular gyri number than the elderly (Figure 5), increasing the possibility that the gyri number decreases with age. The gray matter losses of insula were found in association with age progression, and MRI permits investigation of these morphometric alterations associated with aging in the living human brain [25]. In our study, CS and HG were seen in most of the cases. Noticeable insular topography may be delimited by use of landmarks such as the CS and HG [6].

Present study displayed that many considerable insular morphology characterizations may be demonstrated with clinical MRI at 1.0 T. We used sagittal sections for counting the gyri according to Naidich et al. [6], although Mavridis et al. used transverse 
Table 2. Display of Insular Morphology on Sagittal MR Images

\begin{tabular}{|c|c|c|c|c|c|c|c|c|}
\hline \multirow[b]{2}{*}{$\begin{array}{c}\text { Insular } \\
\text { Gyrus }\end{array}$} & \multicolumn{4}{|c|}{ Right Insula } & \multicolumn{4}{|c|}{ Left Insula } \\
\hline & Well Seen & Poorly Seen & Not Seen & Bifid & Well Seen & Poorly Seen & Not Seen & Bifid \\
\hline PSG & $\begin{array}{c}347 \\
(91.3 \%)\end{array}$ & $\begin{array}{c}22 \\
(5.8 \%)\end{array}$ & 0 & $\begin{array}{c}11 \\
(2.9 \%)\end{array}$ & $\begin{array}{c}352 \\
(92.6 \%)\end{array}$ & $\begin{array}{c}17 \\
(4.5 \%)\end{array}$ & 0 & $\begin{array}{c}11 \\
(2.9 \%)\end{array}$ \\
\hline MSG & $\begin{array}{c}170 \\
(44.7 \%) \\
\end{array}$ & $\begin{array}{c}29 \\
(7.6 \%) \\
\end{array}$ & $\begin{array}{c}179 \\
(47.1 \%)\end{array}$ & $\begin{array}{c}2 \\
(0.5 \%) \\
\end{array}$ & $\begin{array}{c}184 \\
(48.4 \%) \\
\end{array}$ & $\begin{array}{c}30 \\
(7.9 \%) \\
\end{array}$ & $\begin{array}{c}165 \\
(43.4 \%)\end{array}$ & $\begin{array}{c}1 \\
(0.3 \%) \\
\end{array}$ \\
\hline ASG & $\begin{array}{c}307 \\
(80.8 \%) \\
\end{array}$ & $\begin{array}{c}13 \\
(3.4 \%) \\
\end{array}$ & 0 & $\begin{array}{c}59 \\
(15.5 \%) \\
\end{array}$ & $\begin{array}{c}302 \\
(79.5 \%) \\
\end{array}$ & $\begin{array}{c}12 \\
(3.2 \%) \\
\end{array}$ & 0 & $\begin{array}{c}66 \\
(17.4 \%) \\
\end{array}$ \\
\hline PLG & $\begin{array}{c}325 \\
(85.5 \%) \\
\end{array}$ & $\begin{array}{c}12 \\
(3.2 \%) \\
\end{array}$ & $\begin{array}{c}43 \\
(11.3 \%) \\
\end{array}$ & 0 & $\begin{array}{c}323 \\
(85 \%) \\
\end{array}$ & $\begin{array}{c}10 \\
(2.6 \%) \\
\end{array}$ & $\begin{array}{c}47 \\
(12.4 \%) \\
\end{array}$ & 0 \\
\hline ALG & $\begin{array}{c}326 \\
(85.8 \%)\end{array}$ & $\begin{array}{c}11 \\
(2.9 \%)\end{array}$ & $\begin{array}{c}43 \\
(11.3 \%)\end{array}$ & 0 & $\begin{array}{c}323 \\
(85 \%)\end{array}$ & $\begin{array}{c}10 \\
(2.6 \%)\end{array}$ & $\begin{array}{c}46 \\
(12.1 \%)\end{array}$ & $\begin{array}{c}1 \\
(0.3 \%)\end{array}$ \\
\hline CS & $\begin{array}{c}346 \\
(91.1 \%)\end{array}$ & $\begin{array}{c}30 \\
(7.9 \%)\end{array}$ & $\begin{array}{c}4 \\
(1.1 \%)\end{array}$ & NA & $\begin{array}{c}346 \\
(91.1 \%)\end{array}$ & $\begin{array}{c}31 \\
(8.2 \%)\end{array}$ & $3(0.8 \%)$ & NA \\
\hline HG & $\begin{array}{c}378 \\
(99.5 \%)\end{array}$ & $\begin{array}{c}2 \\
(0.6 \%)\end{array}$ & 0 & NA & $\begin{array}{c}371 \\
(97.6 \%)\end{array}$ & $\begin{array}{c}8 \\
(2.1 \%)\end{array}$ & $1(0.3 \%)$ & NA \\
\hline
\end{tabular}

ASG: Anterior Short Gyrus, MSG: Middle Short Gyrus, PSG: Posterior Short Gyrus, ALG: Anterior Long Gyrus, PLG: Posterior Long Gyrus, HG: Heschl's Gyrus, CS: Central Sulcus, NA: Not Applicable

sections for this purpose [15]. Our results confirmed Naidich et al. who reported that sagittal MRIs can be appropriate for numbering the insular gyri [6]. Afif et al. created a two-dimensional template of the human insula obtained from serial sagittal slices [26]. However, the insular gyri pattern can be convoluted, so that MRI may underestimate the real insular gyri number [15].

\section{Conclusion}

The findings of this study demonstrate an insular gyri pattern of handedness and agerelated morphology in Iranian population, with similar gyri pattern in both male and female which may help anatomists, radiologists, and neurosurgeons to more precisely understand the topography of insula and reduce surgical injury. It may be concluded that despite the limitations in detailed definition of insular gyri on MRI, the procedure can be used for clinical application, whenever it is mandatory. In addition, further features of insular anatomy may potentially lead to improved understanding of functional MRI studies and thus of insular function [6]. Researchers can improve future investigations on sex, handedness and agerelated differences in the insula by higher Tesla MRI's and thinner sections in different planes that may yield more accurate data in this regard and is recommended to be considered.

\section{Acknowledgments}

This work was a part of thesis of the medical student and supported by Anatomical Sciences Research Center (ASRC) and Medical Faculty of Kashan University of Medical Sciences (KAUMS). The authors would like to thank Mr. Amir Zavieh, the medical student of KAUMS for his cooperation in this study.

\section{Funding}

None.

\section{Conflicts of Interest}

The authors declare that they have no conflicts of interest.

\section{Authors' Contribution}

Conception and Design: Mohammad Ali Atlasi, Hamid Reza Talari

Data Collection: Mohammad Ali Atlasi, Maryam Montazeri, Hamid Reza Talari

Drafting the Article: Mohammad Ali Atlasi, Esmaeil Fakharian, Hamid Reza Talari Critically Revising the Article: Esmaeil Fakharian, Hossein Akbari

Reviewed Submitted Version of Manuscript: All Authors

Approved the Final Version of the Manuscript: All Authors

\section{References}

1. Ture U, Yasargil DC, Al-Mefty O, Yasargil MG. Topographic anatomy of the insular region. J Neurosurg. 1999;90(4):72033. 
2. Stephani C, Fernandez-Baca Vaca G, Maciunas R, Koubeissi M, Luders HO. Functional neuroanatomy of the insular lobe. Brain Struct Funct.216(2):137-49.

3. Varnavas GG, Grand W. The insular cortex: morphological and vascular anatomic characteristics. Neurosurgery. 1999;44(1):127-36; discussion 36-8.

4. Cheung RT, Hachinski V. The insula and cerebrogenic sudden death. Arch Neurol. 2000;57(12):1685-8.

5. Yasui Y, Breder CD, Saper CB, Cechetto DF. Autonomic responses and efferent pathways from the insular cortex in the rat. J Comp Neurol. 1991;303(3):355-74.

6. Naidich TP, Kang E, Fatterpekar GM, Delman BN, Gultekin SH, Wolfe D, et al. The insula: anatomic study and MR imaging display at $1.5 \mathrm{~T}$. AJNR American journal of neuroradiology. 2004;25(2):222-32.

7. Bidula SP, Kroliczak G. Structural asymmetry of the insula is linked to the lateralization of gesture and language. The European journal of neuroscience. 2015;41(11):1438-47.

8. Faurion A, Cerf B, Van De Moortele PF, Lobel E, Mac Leod P, Le Bihan D. Human taste cortical areas studied with functional magnetic resonance imaging: evidence of functional lateralization related to handedness. Neuroscience letters. 1999;277(3):189-92.

9. Morel A, Gallay MN, Baechler A, Wyss M, Gallay DS. The human insula: Architectonic organization and postmortem MRI registration. Neuroscience. 2013;236:117-35.

10. Afif A, Mertens P. Description of sulcal organization of the insular cortex. Surgical and radiologic anatomy: SRA. 2010;32(5):491-8.

11. Guenot M, Isnard J, Sindou M. Surgical anatomy of the insula. Advances and technical standards in neurosurgery. 2004;29:265-88.

12. Chee MW, Zheng H, Goh JO, Park D, Sutton BP. Brain structure in young and old East Asians and Westerners: comparisons of structural volume and cortical thickness. Journal of cognitive neuroscience. 2011;23(5):1065-79.

13. Panizzon MS, Fennema-Notestine C, Eyler LT, Jernigan TL, Prom-Wormley E, Neale M, et al. Distinct genetic influences on cortical surface area and cortical thickness. Cereb Cortex. 2009;19(11):2728-35.

14. Brickman AM, Schupf N, Manly JJ, Luchsinger JA, Andrews H, Tang MX, et al. Brain morphology in older African Americans, Caribbean Hispanics, and whites from northern Manhattan. Arch Neurol. 2008;65(8):1053-61.

15. Mavridis I, Boviatsis E, Anagnostopoulou S. Exploring the neurosurgical anatomy of the human insula: a combined and comparative anatomic-radiologic study. Surgical and radiologic anatomy : SRA. 2011;33(4):319-28.

16. Kennedy DN, Lange N, Makris N, Bates J, Meyer J, Caviness VS, Jr. Gyri of the human neocortex: an MRIbased analysis of volume and variance. Cereb Cortex. 1998;8(4):372-84.

17. Kertesz A, Polk M, Black SE, Howell J. Sex, handedness, and the morphometry of cerebral asymmetries on magnetic resonance imaging. Brain research. 1990;530(1):40-8.

18. Gao Q, Wang J, Yu C, Chen H. Effect of handedness on brain activity patterns and effective connectivity network during the semantic task of Chinese characters. Scientific reports. 2015;5:18262.

19. Narr KL, Bilder RM, Luders E, Thompson PM, Woods RP, Robinson $\mathrm{D}$, et al. Asymmetries of cortical shape: Effects of handedness, sex and schizophrenia. NeuroImage. 2007;34(3):939-48

20. Chiarello C, Vazquez D, Felton A, Leonard CM. Structural asymmetry of anterior insula: behavioral correlates and individual differences. Brain and language. 2013;126(2):109-22.

21. Coffey CE, Lucke JF, Saxton JA, Ratcliff G, Unitas LJ, Billig B, et al. Sex differences in brain aging: a quantitative magnetic resonance imaging study. Arch Neurol. 1998;55(2):169-79.
22. Alexander GE, Chen K, Merkley TL, Reiman EM, Caselli RJ, Aschenbrenner M, et al. Regional network of magnetic resonance imaging gray matter volume in healthy aging. Neuroreport. 2006;17(10):951-6.

23. Bergfield KL, Hanson KD, Chen K, Teipel SJ, Hampel

$\mathrm{H}$, Rapoport SI, et al. Age-related networks of regional covariance in MRI gray matter: reproducible multivariate patterns in healthy aging. NeuroImage. 2010;49(2):1750-9.

24. Sussman D, Leung RC, Chakravarty MM, Lerch JP, Taylor MJ. Developing human brain: age-related changes in cortical, subcortical, and cerebellar anatomy. Brain and behavior. 2016;6(4):e00457.

25. Terribilli D, Schaufelberger MS, Duran FL, Zanetti MV, Curiati PK, Menezes PR, et al. Age-related gray matter volume changes in the brain during non-elderly adulthood. Neurobiology of aging. 2011;32(2):354-68.

26. Afif A, Hoffmann D, Becq G, Guenot M, Magnin M, Mertens P. MRI-based definition of a stereotactic twodimensional template of the human insula. Stereotactic and functional neurosurgery. 2009;87(6):385-94.

\section{Comments}

I read with great interest the paper of Atlasi et al. which investigates MRI-based morphology of the human insula in an Iranian population and have mainly following suggestions: they should give credit to the existing literature on insular morphology and remove the term occasionally in the abstract. They mention that "In present study, it was shown that younger subjects have more insular gyri number than the elderly" This conclusion needs intra-individual longitudinal studies over decades; for sure, atrophy of insular gyri can be observed as in any other brain cortex; but explanation of gyrus disappearance by the age might not be confirmed by the present study. Also, the indication for MRI is not mentioned. Although direct insular pathology was not expected, other indirect pathologies affecting insular should be ruled out. On the other hand, they emphasize that higher tesla MRI may clarify the results. This needs more detailed assessment with higher resolution MRI with thinner sections in different planes. In general, they have an intelligent approach to investigate the human brain based on MRI and had a valuable protocol and study.

Mohammad Javad Mirzayan

Assistant Professor of Neurosurgery, Medical University of Hannover, European Medical University of Oldenburg, Germany 